\title{
Cardápio Legislativo: \\ opções e contradições da regulação \\ urbana na produçãoo de lotes \\ nas capitais brasileiras
}

\author{
Gisela Cunha Viana Leonelli, \\ Lais Candiotto Medeiros, Marla Jéssica Marinho*
}

\begin{abstract}
Resumo Um intenso fenômeno de condominiarização tem sido observado em capitais brasileiras. O conhecimento dos impactos negativos produzidos pela expansão urbana murada não tem revertido o avanço dos condomínios horizontais fechados. Neste contexto, o objetivo é discutir qual o papel das legislações das capitais brasileiras para a produção do lote urbanizado na cidade intramuros. Após discussão sobre o marco regulatório de parcelamento do solo e da legalidade dos condomínios horizontais fechados, são identificadas e analisadas as formas de produção de lote urbano permitidas pelas leis dos municípios estudados. Conclui-se que as capitais brasileiras têm apresentado um cardápio legislativo sobre a produção de lotes urbanos, onde a regra é opcional e a flexibilização é a escolha.
\end{abstract}

Palavras-chave: leis de parcelamento do solo urbano, condomínio fechado, capitais brasileiras. Laws Menu: options and contradictions of ur-
ban regulation on the lot production in Brazilian
capitals
Abstract Recently, high urbanization rates and intense phenomenon of gated communities has been observed in the Brazilian capitals. The knowledge of the negative impacts produced by the walled urban sprawl has not reversed the advance of gated communities. In this article, we will discuss the role of Brazilian capitals laws for the production of the urbanized lot in the city between walls. It will be presented a brief discussion of the regulatory framework of land division and legality of gated communities. They are subsequently identified and analyzed forms of urban lot permitted by the municipalities laws studied. We conclude that the Brazilian capitals have presented a legislative menu on the production of urban lots, where the rule is optional and flexible is the choice.

Keywords: urban land division laws, gated community, Brazilian capitals.
Menu Legislativo: opciones y contradicciones de la regulación urbana en la producción de lotes en las capitales brasileñas

Resumen Un intenso fenómeno de condominiarización ha sido observado en capitales brasileñas. El conocimiento de los impactos negativos producidos por la expansión urbana murada no ha revertido el avance de los condominios horizontales cerrados. En este contexto, el objetivo es discutir cuál es el papel de las legislaciones de las capitales brasileñas para la producción del lote urbanizado en la ciudad intramuros. Después de la discusión sobre el marco regulatorio de parcelamiento del suelo y de la legalidad de los condominios horizontales cerrados, se identifican y analizan las formas de producción de lote urbano permitidas por las leyes de los municipios estudiados. Se concluye que las capitales brasileñas han presentado un menú legislativo sobre la producción de lotes urbanos, donde la regla es opcional y la flexibilización es la elección.

Palabras clave: leyes de parcelación del suelo urbano, condominio cerrado, capitales brasileñas. 


\section{Urbanização intensiva e condominiarização}

No início do século XXI, com exceção dos territórios estagnados, muitas cidades brasileiras continuam em expansão, intensificando o processo de urbanização brasileiro. Os processos migratórios, a metropolização da pobreza e a desigualdade socioterritorial são dinâmicas simultâneas com a concentração da população nas grandes cidades brasileiras (Brito, 2005).

Em 2012, a maioria dos estados brasileiros apresentou alta taxa de urbanização (Gráfico 1). Destacam-se os estados do Rio de Janeiro com 97\%, o de São Paulo com $96 \%$ e de Goiás com 91\% (IBGE, 2012), sendo que a taxa de urbanização do país foi de $84,8 \%$ no mesmo período.

Os dados recentes do IBGE (2013) confirmam taxas de urbanização ainda mais expressivas nas maiores regiões metropolitanas brasileiras (tabela1), com índices que se aproximam a quase $100 \%$ da população residindo em áreas urbanas.

A partir de do início do séc XX, na maioria das capitais dos estados brasileiros é possível verificar áreas com consolidada urbanização e verticalização, mas também processos de expansão horizontal de seu tecido urbano, com destaque para três tipologias de moradia: a) assentamentos informais (favelas e loteamentos clandestinos), b) conjuntos habitacionais do Programa Minha Casa Minha Vida e c) loteamentos e condomínios horizontais fechados.

Os estudos sobre a intensificação da urbanização acompanhada por processos de segregação urbana e da condominiarização da produção do espaço tem sido tratados no Brasil há mais de duas décadas. (Caldeira, 1997, 2000; Baltrusis e D’Ottaviano, 2009; Lima, 2009; Sposito e Góes, 2013). Entende-se por condominiarização a opção residencial por condomínios e loteamentos fechados. Caldeira (2000) descreve este novo estilo de vida das cidades brasileiras como a experiência de viver atrás de muros e vigiados por seguranças, cunhando estes espaços com o termo "enclaves

* Gisela Cunha Viana Leonelli é Arquiteta e Urbanista, professora da Faculdade de Engenharia Civil, Arquitetura e Urbanismo da Universidade Estadual de Campinas, ORCID <https://orcid.org/00000002-2371-3092>. Lais Candiotto Medeiros é Arquiteta e Urbanista, mestranda da Universidade Estadual de Campinas, ORCID <http://orcid.org/00000003-4409-7193>. Marla Jéssica Marinho é Arquiteta e Urbanista, Universidade Estadual de Campinas, ORCID $<$ http://orcid.org/0000-00021922-7905> fortificados" (Caldeira, 2000. p.257). Ainda não há dados quantitativos sobre a produção de condomínios horizontais e loteamentos fechados no Brasil, mas há vários estudos discutindo o fenômeno em cidades específicas. A partir do estudo da Região Metropolitana de Belo Horizonte, Gonçalves e Marra (2012) denunciam a partir do artigo intitulado como "Privatização do planejamento urbano pelos condomínios horizontais" o avanço dos empreendimentos residenciais naquela região. Marinho e Leonelli (2017) demonstram que em 2016 na cidade de Indaiatuba -SP, $25 \%$ de sua mancha urbana se encontrava privatizada e fechada intramuros, com $17 \%$ da população moradora do município. Lage (2017) discute o aumento do número destes empreendimentos em Uberlândia - MG a partir de 1990 e o impacto urbanístico nas cidades médias. Braga (2013) também pauta a predominância dos loteamentos fechados nas cidades brasileiras a partir do exemplo de Piracicaba - SP. 
Gráfico 1: Taxa de Urbanização - Unidades Federativas do Brasil. Elaborado pelas autoras. Fonte: IBGE, 2013. Síntese de Indicadores Sociais: Uma Análise das Condições de Vida da População Brasileira.

Tabela 1: Taxa de Urbanização de Regiões Metropolitanas Brasileiras. Elaborado pelas autoras. Fonte: IBGE, 2013. Síntese de Indicadores Sociais. Uma Análise das Condições de Vida da População Brasileira.

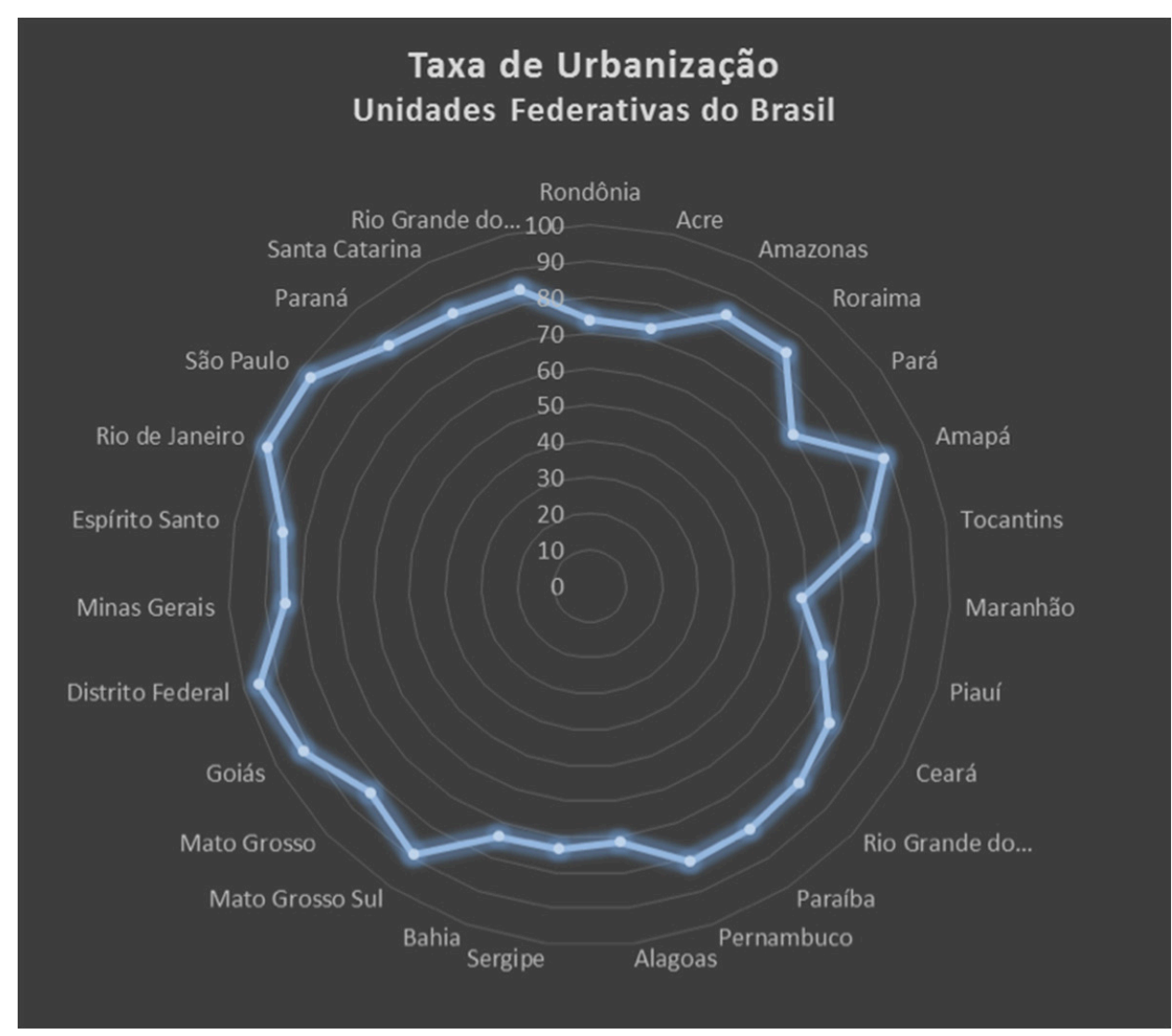

\begin{tabular}{ll}
\hline Regiões Metropolitanas & Taxa de Urbanização \\
\hline RM Belém & 97,3 \\
\hline RM Fortaleza & 95,8 \\
\hline RM Recife & 97,5 \\
\hline RM Salvador & 98,3 \\
\hline RM Belo Horizonte & 97,5 \\
\hline RM Rio de Janeiro & 99,5 \\
\hline RM São Paulo & 98,9 \\
\hline RM Curitiba & 92,5 \\
\hline RM Porto Alegre & 96,7 \\
\hline
\end{tabular}


A recente tese de Turczyn (2019) traz a espacialização dos enclaves fortificados de toda a Região Metropolitana de Campinas e a formação de "mutações urbanas" decorrentes desta forma de urbanização, comprovando o quão é intensa e significativa a presença destas na estruturação do território metropolitano investigado.

A urbanização via condominarização horizontal é mais recorrente e favorecida no que Leonelli (2013) intitula como "cidades que parcelam", caracterizadas como aquelas que possuem na abertura de novos parcelamentos sua principal forma de urbanização e ainda apresentam estoque de glebas rurais e urbanas para ser parcelado. A tipologia da casa unifamiliar construída em lote isolado é a forma de moradia predominante nas "cidades que parcelam", caracterizadas com baixas e médias densidades populacionais e construtivas e reduzida verticalização. (Leonelli, 2013)

Apesar de não ser o foco deste artigo, faz-se necessário registrar que os impactos da produção dos enclaves fortificados (Caldeira, 2000) na produção do espaço urbano term ocupado o debate e as pesquisas científicas com destaque para temas como: privatização de áreas públicas, violência urbana, incentivo à cidade espraiada, bloqueio da mobilidade e segregação socioterritorial. (Sposito, 2007; Silva, 2009; Lima, 2009). A partir de estudos das "villes privées" na América Latina, Europa, Ásia e Oceania, Parquot (2009) constata que este é um processo de urbanização planetário.

Diante do fenômeno da condominiarização no Brasil e dos seus impactos sociourbanisticos comprovados cientificamente, a proposta apresentada neste artigo é de discutir qual o papel das legislações das capitais brasileiras frente à intensificação desta forma de urbanização. A legislação urbanística proíbe, controla, induz, inibe ou promove a cidade fechada? Qual o impacto das leis vigentes frente a este tipo de urbanização? Para tanto, este trabalho está estruturado da seguinte forma: breve discussão sobre o marco regulatório de parcelamento do solo federal e legalidade dos condomínios horizontais fechados; levantamento e análise das tipologias de parcelamento do solo permitidas em todas as capitais brasileiras e considerações sobre o papel da regulação urbanística das capitais brasileiras quanto ao parcelamento do solo urbano.

\section{Parcelamento do solo urbano e condomínios horizontais: a diferença que interessa}

A célula básica do tecido urbano é o lote. Lote é a terra urbanizada, com infraestrutura, apta para receber edificação, é o produto do processo de parcelamento do solo. A produção do lote no Brasil pode ser feita a partir de duas tipologias: desmembramento e loteamento (Lei Federal 6.766). A tipologia "desmembramento" é adotada quando não há necessidade de abertura ou prolongamento do sistema viário para o parcelamento do solo e a tipologia "loteamento" é quando há esta necessidade para se ter acesso ao lote. Ao se lotear, há a doação de áreas institucionais, áreas para o sistema de lazer e o sistema viário; sendo que todas estas devem ser públicas. A produção de lotes, no Brasil, é regrada pela lei federal (L.F. 6.766/79 e suas alterações) e pelas leis municipais de parcelamento do solo urbano. Segundo a Pesquisa de Informações Básicas Municipais, de 2015, mais de $61 \%$ dos municípios brasileiros possuem leis que regulam a prática de parcelamento do solo, sendo esta uma das principais leis urbanísticas encontradas nas administrações municipais, conforme apresentado no gráfico a seguir. 
Gráfico 2: Legislações Urbanísticas Municipais - Brasil. Elaborado pelas autoras. Fonte: IBGE, 2013. Síntese de Indicadores Sociais: Uma Análise das Condições de Vida da População Brasileira.

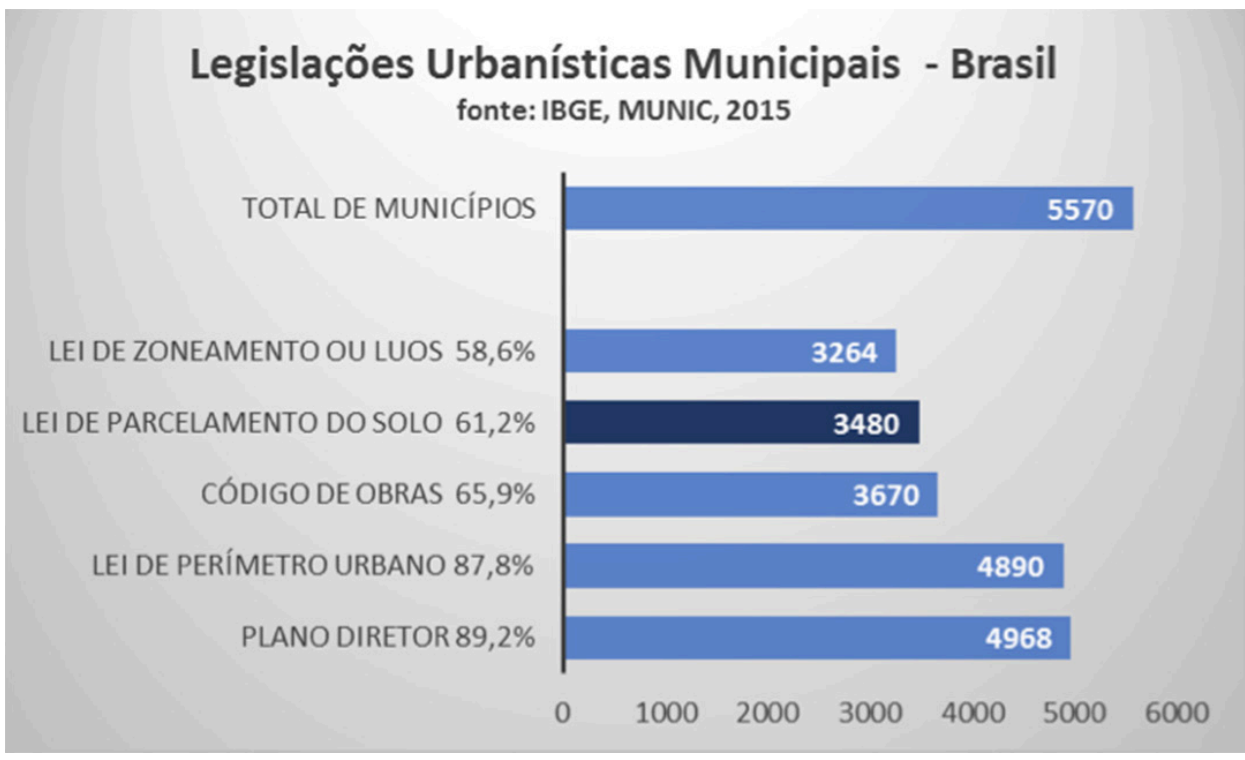

Ao se implantar condomínios horizontais fechados, morfologicamente e urbanisticamente, fica evidente que se está produzindo terra urbanizada para receber edificação, portanto há o parcelamento do solo. Ocorre a criação de novo tecido urbano com a necessidade de abertura de sistema viário para viabilizar o acesso ao lote. Neste caso, considera-se nítida e explícita a forma de burla à lei federal de parcelamento do solo urbano para escape das exigências previstas para a implantação de loteamento, com o agravamento da produção da cidade murada. (Autora, 2013, 2015).

A opção mais frequente para viabilizar a "legalidade" da expansão urbana via empreendimentos horizontais fechados são três: a) aprovação de loteamento e seu posterior fechamento b) utilização da Lei Federal 4591/1964 que trata de incorporação imobiliária como substituta da lei federal de parcelamento do solo urbano e c) criação de legislações municipais para aprovação de condomínios horizontais fechados. As três opções eram conflitantes e ilegais frente à lei federal de parcelamento do solo urbano (até sua alteração pela L. F. 13.465/17 a ser apresentada abaixo).

Condomínio horizontal fechado e loteamento possuem regimes de propriedades diferentes, mas resultados urbanísticos similares, pois ambos estão produzindo lote. Ressaltar a diferença do regime de propriedade como se ela também ocorresse urbanisticamente interessa para o escape da lei de parcelamento do solo e doação de áreas públicas.

\section{Condomínio vertical, condomínio horizontal e a uma lei fora do lugar}

Compreender como forma de produzir lotes o loteamento, mas não o condomínio horizontal fechado interessa para a difusão do modelo da condominiarização da 
expansão urbana. Esta diferença é fundamental para que leis municipais reproduzam o aparato legal que permitam esta tipologia de urbanização e atenda o intenso mercado voltado para este produto imobiliário existente no país. Neste caso, o argumento legal adotado é que só há produção de lotes quando há loteamento, no caso de condomínios horizontais não há lotes, e sim fração ideal da gleba. Pois bem, lote e fração ideal são distintos enquanto ao regime de propriedade, pois o lote tem sua matrícula de propriedade individualizada enquanto que a fração ideal é parte de uma matrícula. Como já apontado, urbanisticamente, tanto o condomínio horizontal como o loteamento apresentam produtos idênticos: porção de terra isolada, infraestruturada, com acesso ao sistema viário, apta à edificação individualizada. A distinção a partir da regulação da propriedade privada é utilizada para escapar da evidente similaridade urbanística: ambos produzem lote urbanizado.

Várias legislações municipais de parcelamento do solo estipulam que as categorias de parcelamento vigentes são loteamento e desmembramento. No entanto, em uma lei paralela, criam a categoria de condomínios horizontais argumentando que não se trata de parcelamento do solo, mas sim de condomínios. O argumento de se tratar de condomínio e não de loteamento é utilizado para escapar da criação "legal" de uma nova categoria de parcelamento do solo, o que seria contrário à Lei $n^{\circ}$ 6.766/79. Porém, qualquer legislação que permite condomínios horizontais fechados está criando uma nova categoria de parcelamento do solo não prevista pela lei federal brasileira de parcelamento do solo urbano. O pretexto legal utilizado para respaldar os condomínios horizontais fechados é o desvirtuamento da Lei Federal ${ }^{\circ}$ 4.591/1964 que trata do regime jurídico de propriedade em condomínios. Utiliza-se uma lei que tem como função regulamentar o regime de propriedade para outro objetivo: o de se parcelar o solo urbano. Regime de propriedade cabe ao Código Civil, enquanto parcelamento do solo urbano é matéria de Direito Urbanístico. Aplicar um pelo outro, é no mínimo, subverter seus princípios e objetivos.

Para ilustrar a correta aplicação Lei Federal n 4.591/1964, cabe elucidar a distinção entre condomínios horizontais fechados e condomínios verticais. Nos dois casos, não há matrículas de propriedades individuais, mas sim fração-ideal da propriedade, sendo que no segundo é para burlar a lei urbanística. Nos condomínios verticais, os edifícios construídos são implantados em lotes resultantes de glebas já parceladas, onde o sistema viário bem como as outras áreas públicas já foram devidamente destinados. Neste caso, a Lei Federal n 4.591/1964 é aplicada coerentemente, por exemplo: para disciplinar o regime de propriedade de um apartamento existente em um edifício com vários andares, implantado em um único lote. A fração ideal significa a quantidade de propriedade que o titular da unidade tem nas partes comuns do condomínio. O lote, sobre o qual foi construído um prédio verticalizado é parte comum de vários proprietários, portanto é utilizada a fração ideal.

Diferentemente dos condomínios verticais, em condomínios horizontais fechados ocorre a subdivisão da gleba em "pseudo-lotes", com abertura de sistema viário privatizado para construção de unidades unifamiliares horizontais autônomas e a criação de espaços coletivos, mas não públicos. O fechamento do empreendimento é imperativo, sendo que há casos em que áreas públicas são destinadas extramuros. 
1 Sobre o entendimento de que há a produção de lote na implantação de condomínios horizontais fechados - e, portanto, ocorre o escape da legislação de parcelamento do solo - não há consenso. Os trabalhos de Freitas, (1989), Cordeiro (2003), Lima (2009) e Autora (2013) apresentam o quadro de posições diversas sobre a legalidade dos condomínios e loteamentos fechados frente a L. F. 6.766.
2 Para acompanhar o julgamento da ADIN, consultar <http://redir. stf.jus.br/estfvisualizadorpub/ jsp/consultarprocessoeletronico/ConsultarProcessoEletronico. jsf? seqobjetoincidente $=5255150$ egulamentos.
Mas a diferença fundamental entre os condomínios verticais e os condomínios horizontais é o impacto urbanístico. Os primeiros, por serem edificados em áreas já parceladas estão inseridos na malha urbana enquanto que os condomínios horizontais fechados comprometem a mobilidade urbana, privatizam áreas públicas, acirram a criação de guetos sociais. É importante ressaltar que a inconstitucionalidade das leis de condomínios horizontais fechados em relação a L.F. 6.766/79 é apenas uma derivação do problema real, que é o sociourbanístico. Ao se legalizar ${ }^{1}$ a expansão urbana murada, abandona-se a produção da cidade aberta, integrada, com espaços públicos e de uso democrático. Impera a cidade fragmentada, isolada, individualizada, de tecidos homogêneos e esgarçados.

\section{A legalização federal dos condomínios horizontais e loteamen- tos fechados no governo Temer}

Apesar de toda a explanação sobre as estratégias de escape da regra federal de parcelamento do solo e da ilegalidade de se fechar loteamentos apresentada acima, o governo do ex-presidente Michel Temer foi marcado pelo desmanche da política urbana ao aprovar a Nova Lei de Regularização Fundiária que, entre muitas retrocessos e flexibilizações, permite a regularização das urbanizações fechadas.

A Lei n 13.465, denominada como "Nova" lei de Regularização Fundiária foi aprovada nas últimas horas do dia 11 de julho de 2017 frente a muitas críticas, resistências e questionamentos, em especial dos defensores da reforma urbana (Guimarães, 2017, Magalhães, 2017). Além de muitas alterações em relação à regularização fundiária destinada à baixa renda e a regularização da terra urbana e rural, esta lei - desdobramento da MP 759 - incorporou uma demanda antiga do setor imobiliário: viabilizar na lei federal os empreendimentos horizontais fechados, alterando a L.F. 6766.

As duas modalidades de parcelamento do solo continuam sendo loteamento e desmembramento. No entanto, a nova Lei Federal no 13.465/17 prevê a categoria de loteamento de acesso controlado, a ser regulamentado pelo município (Cap I, Art. $2^{\circ}, \S 4^{\circ}$ ). A lei também prevê que o lote, produto do parcelamento do solo, pode ser constituído sob a forma de imóvel autônomo ou de unidade imobiliária integrante de condomínio de lotes. (Cap I, Art. $2^{\circ}, \S 7^{\circ}$ ). Vitória do setor imobiliário, que há décadas tentava incluir o condomínio horizontal e o loteamento fechado na lei federal de parcelamento do solo urbano para contrapor os inúmeros questionamentos e conflitos que estas modalidades de urbanização apresentavam em relação à L. F. 6766. Esta insistência e conquista feita a fórceps para incluir a viabilidade do loteamento fechado e dos condomínios horizontais na L.F. 6766 só confirma o quanto estas duas modalidades de urbanização tinham um respaldo legislativo frágil e questionável.

A segurança jurídica trazida pela Lei n 13.465/2017 também não se encontra estabilizada já que se encontra no Supremo Tribunal Federal a Ação Direta de Inconstitucionalidade - ADIN 5771, cuja relatoria é do ministro do Superior Tribunal da Justiça Luiz Fux e se encontra em fase de análise para posterior julgamento ${ }^{2}$. O argumento do procuradorgeral da República, o Rodrigo Janot Monteiro de Barros, ao pedir a suspensão integral da lei, foi de que a vigência da Nova Lei de Regularização Fundiária (Lei 13.465/2017) permitirá a privatização em massa de bens públicos, intensificará os conflitos fundiários e aumentará a concentração fundiária ao atender interesses do mercado imobiliário 
${ }^{3}$ Até o momento, a pesquisa teve apoio financeiro de duas agências de fomento a partir dos seguintes projetos de pesquisa: Parcelamento do Solo nas Capitais do Brasil: a lei e a prática, financiada pelo CNPq; Marco legal da produção de loteamentos das capitais brasileiras do Norte e Centro-Oeste: (des) alinhamentos com a lei federal de parcelamento do solo, financiada pela FAPESP. e de especuladores urbanos e rurais (Ministério Público Federal - Procuradoria Geral da República No 220.490/2017-AsJConst/SAJ/PGR).

\section{As leis das capitais brasileiras para produção de lotes}

Este artigo é resultante de uma pesquisa que teve como objetivo construir um quadro analítico sobre a base legal que regulamenta a prática de parcelamento do solo no Brasil ${ }^{3}$ vigente até 2016. Foram levantadas as tipologias de produção de lotes previstas nas legislações das capitais brasileiras. Como tipologias de parcelamento foram adotadas não só as previstas na Lei Federal 6.766/79, mas também suas variações, deformações e adaptações encontradas nas leis e aplicadas pelos governos das capitais. Nesta pesquisa, são entendidas como tipologias de parcelamento as formas praticadas de produção do solo urbanizado.

O recorte adotado a partir das leis das capitais deve-se a dois fatores: a) a maioria das capitais brasileiras apresenta altas taxas de urbanização e ainda está produzindo lotes, mesmo que seja em condomínios horizontais; podendo ser em áreas de expansão ou em vazios urbanos; b) as leis urbanísticas vigentes nas capitais são referências legislativas para os outros municípios, pertencentes a regiões metropolitanas ou no interior dos estados. As tipologias de parcelamento, os parâmetros e as exigências urbanísticas, as flexibilizações e distorções legislativas bem como os procedimentos administrativos praticados nas capitais brasileiras são replicados nas outras cidades.

Metodologicamente, procurou-se levantar o marco regulatório municipal que tratam do parcelamento do lote em diversas leis: lei de parcelamento do solo municipal, lei de uso e ocupação do solo, planos diretores, código de obras, código de urbanismo, decretos-leis e leis complementares. O material foi levantado por intermédio de sites eletrônicos das prefeituras e câmaras municipais, sites legislativos especializados e a partir de solicitação direta à órgãos administrativos e algumas entrevistas presencias em secretarias administrativas das cidades pesquisadas. Houve baixo índice de retorno das prefeituras; desta forma o material foi sistematizado a partir do que está público e disponibilizado pelos municípios.

O objetivo principal foi identificar e analisar as tipologias de produção de lotes previstas nas capitais brasileiras. O resultado revelou um cardápio de leis sobre o parcelamento do solo urbano, onde é possível escolher como expandir a cidade: de forma aberta ou fechada, regulada ou flexível.

\section{Regular para permitir}

Os dados levantados mostraram que todas as capitais brasileiras adotam a figura do loteamento e desmembramento da L.F. 6.766 e, no mínimo, uma forma de produção de lotes via empreendimento horizontal fechado. Em todo os casos é possível parcelar o solo em morfologias abertas e fechadas, dependendo do empreendedor decidir em qual das categorias pretende realizar o investimento.

As diversas tipologias encontradas foram sistematizadas em dois grupos: a) Formas de produção de lotes, que não necessariamente produzam empreendimentos fechados b) Formas fechadas de produção de lotes, direcionadas para condomínios horizontais fechados e suas variações. 
Tabela 2: Formas de produção de lotes previstas nas leis das capitais brasileiras. Fonte: tabela elaborada pelas autoras.
Desdobro, arruamento, remembramento, reparcelamento e conjunto habitacional como loteamento foram tipologias de parcelamento do solo encontradas além do loteamento e desmembramento. A permissão do loteamento na zona rural também foi encontrada, mesmo sendo proibido pela lei federal, como demostrado na tabela abaixo:

\begin{tabular}{|c|c|c|c|c|c|c|c|c|c|}
\hline Capit & Brasileiras & 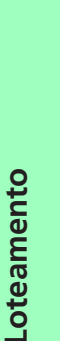 & 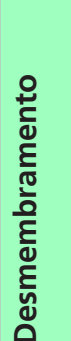 & $\begin{array}{l}\text { 옹 } \\
\text { 응 } \\
\text { 임 }\end{array}$ & 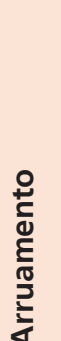 & 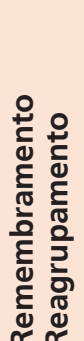 & 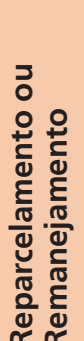 & 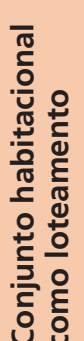 & 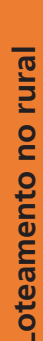 \\
\hline & Porto Velho (RO) & $x$ & $x$ & & & & & & \\
\hline & Rio Branco (AC) & $x$ & $x$ & $x$ & & $x$ & & & \\
\hline & Manaus (AM) & $x$ & $x$ & & & & & & \\
\hline & Boa Vista (RR) & $x$ & $x$ & $x$ & $x$ & $x$ & & & \\
\hline & Belém (PA) & $x$ & $x$ & & $x$ & $x$ & & & \\
\hline$\stackrel{ \pm}{2}$ & Macapá (AP) & $x$ & $x$ & $x$ & & & & & \\
\hline & Palmas (TO) & $x$ & $x$ & & & & & & \\
\hline & São Luís (MA) & $x$ & $x$ & $x$ & $x$ & $x$ & $x$ & & \\
\hline & Teresina $(\mathrm{PI})$ & $x$ & $x$ & $x$ & $x$ & $x$ & & & $x$ \\
\hline & Fortaleza (CE) & $x$ & $x$ & & $x$ & $x$ & & & \\
\hline & Recife (PE) & $x$ & $x$ & & & $x$ & & & \\
\hline & Natal (RN) & $x$ & $x$ & & & & & & \\
\hline & João Pessoa (PA) & $x$ & $x$ & & $x$ & $x$ & & & $x$ \\
\hline$\stackrel{0}{n}$ & Maceió (AL) & $x$ & $x$ & & & & & & \\
\hline 훙 & Aracaju (SE) & $x$ & $x$ & & $x$ & $x$ & & & \\
\hline & Salvador (BA) & $x$ & $x$ & & & $x$ & & & \\
\hline & Campo Grande (MS) & $x$ & $x$ & & & & & & $x$ \\
\hline & Cuiabá (MT) & $x$ & $x$ & $x$ & & $x$ & & & $x$ \\
\hline$\stackrel{\vec{n}}{\tilde{n}}$ & Goiânia (GO) & $x$ & $x$ & & & & & & \\
\hline & Brasília (DF) & $x$ & $x$ & & & & & & $x$ \\
\hline & Belo Horizonte (MG) & $x$ & $x$ & $x$ & & $x$ & $x$ & & \\
\hline & Vitória (ES) & $x$ & $x$ & $x$ & & $x$ & & & \\
\hline$\frac{0}{0}$ & Rio de Janeiro (RJ) & $x$ & $x$ & & & $x$ & & & \\
\hline & São Paulo (SP) & $x$ & $x$ & & & $x$ & $x$ & & \\
\hline & Curitiba (PR) & $x$ & $x$ & & $x$ & & & & \\
\hline & Florianópolis (SC) & $x$ & $x$ & & & & $x$ & $x$ & \\
\hline$n$ & Porto Alegre (RS) & $x$ & $x$ & & & & & & \\
\hline
\end{tabular}


Tabela 3: Formas fechadas de produção de lotes previstas nas leis das capitais brasileiras. Fonte: tabela elaborada pelas autoras.
Para entendimento do impacto na produção do espaço urbano nas cidades estudadas, as formas de produção de lote da Tabela 1 demandam aprofundamento quanto sua aplicação. Especialmente as figuras do arruamento, remembramento e reparcelamento podem suscitar desvios das exigências exigidas no loteamento.

Destacaram-se, em uma sistematização específica, as formas fechadas de produção de lotes previstas nas legislações municipais estudadas, apresentadas na tabela abaixo:

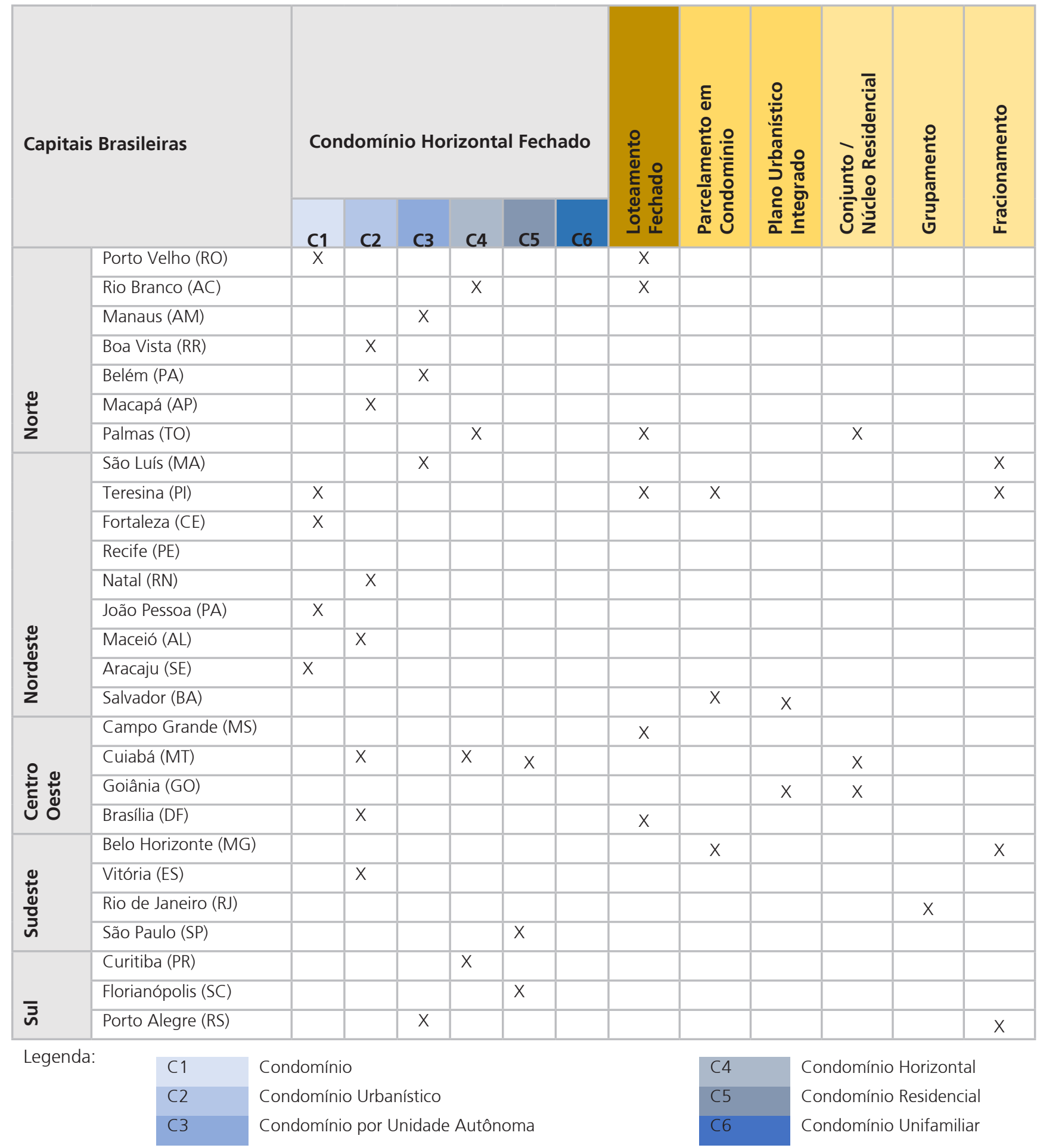


Paralela às formas de produção de lotes apresentadas na tabela 2, foram identificadas várias formas de produção de lotes de forma fechada: 1) condomínio horizontal (desdobrado em seis variações), 2) loteamento fechado; 3) parcelamento em condomínio; 4) plano urbanístico integrado; 5) conjunto ou núcleo residencial fechado, 6) grupamento e 7) fracionamento.

\section{Derivações "legais" para o condomínio horizontal fechado}

A figura do condomínio horizontal fechado é adotada por diferentes nomeclaturas: condomínio, condomínio urbanístico, condômino por unidade autônoma, condomínio horizontal, condomínio residencial e condomínio unifamiliar.

Nas legislações levantadas das capitais da região Norte, todas permitem a prática de condomínios horizontais fechados, sendo que Porto Velho, Rio Branco e Palmas também admitem o loteamento fechado. Palmas também oferece uma terceira alternativa: os conjuntos residenciais, que poderão seguir as regras de desmembramentos (sem deixar áreas públicas). A lei de Macapá e a de Belém não distinguem condomínios horizontais de condomínios verticais, se valendo do entendimento que também tem a lei de Manaus ao interpretar a L. F. nº 4591/1964 que trata de incorporação imobiliária como sendo uma lei de parcelamento do solo urbano.

Na região Nordeste, as legislações de São Luís, Natal, Maceió e Aracaju consideram condomínios urbanísticos em unidades autônomas como uma modalidade de parcelamento do solo, uma vez que na prática são produzidos "lotes" para unidades autônomas com abertura de sistema viário. João Pessoa equipara o loteador ao incorporador e remete a L. F. n 4591/1964 para viabilizar os condomínios horizontais.

Teresina é capital nordestina que apresenta a legislação mais permissiva, abusiva e conflitante com a Lei 6.766. Define como arruamento a divisão de glebas em quadras, mediante a abertura de novas vias de circulação ou através do prolongamento ou ampliação das vias já existentes, sendo que esta é a definição de loteamento da lei federal. Também prevê a figura do fracionamento como sendo o parcelamento de terrenos ou glebas, isento de doação dos percentuais destinados ao uso público, quando ocorrer em terrenos ou glebas com área de até 10.000 m2. Ou seja: através do fracionamento é possível subdividir a gleba até a metragem de um quarteirão sem deixar área pública. Como se não bastasse todas estas possibilidades de deformação da prática de parcelamento, a lei ainda prevê a tipologia parcelamento para implantação de loteamentos fechados como aquele consequente da permissão do poder público, de fechamento de quadras de parcelamentos tradicionais.

Frente a tanta flexibilidade legislativa, a lei de Fortaleza destoa das outras citadas acima ao prever os condomínios por unidades autônomas e restringir sua implantação em áreas parceladas.

Na região Centro-Oeste, Campo Grande oferece sete possibilidades de produção de lotes: loteamento padrão, loteamento de interesse social, loteamento fechado, loteamento industrial, urbanização integrada de interesse social, loteamento na área rural, loteamento fechado na área rural. As variações de loteamento são tantas que nem é preciso estabelecer condomínios horizontais fechados, uma vez que é possível 
lotear e fechar, inclusive na área rural. A legislação de Cuiabá adota a definição de condomínio horizontal ou conjunto residencial horizontal. Na modalidade "unidades habitacionais isoladas" o resultado é o mesmo que a lote individualizado do loteamento. Também na regulação de Cuiabá é permitido o parcelamento em área rural, na categoria sítio de recreio. Goiânia possui uma categoria específica: o plano urbanístico integrado, mas que internamente também possibilita núcleos residenciais fechados. Brasília permite o loteamento fechado, condomínio urbanístico (pela L. F. 4.591/64) e parcelamento na macrozona rural.

Na região Sudeste, Belo Horizonte adota "loteamento e desmembramento" como modalidades de parcelamento de solo e "parcelamento para condomínios" como categorias de parcelamento do solo. Vitória também se ampara na Lei Federal $n^{\circ}$ 4.591/64 para estipular o parcelamento do solo via condomínios por unidades autônomas e mitiga esta flexibilização ao definir área máxima do condomínio até $20.000 \mathrm{~m}^{2}$ e frente máxima ao equivalente a cinco quadras. Já no Rio de Janeiro, as variações dos condomínios horizontais fechados são denominadas "grupamentos de áreas privativas".

Na cidade de São Paulo, a recém aprovada lei de Zoneamento e Parcelamento do Solo $n^{\circ}$ 1640/2016 permite o conjunto residencial horizontal por casa isoladas como uma categoria de uso residencial e não revogou a lei de condomínios horizontais fechados criada em 2004.

Na região Sul, para garantir a legalidade dos condomínios horizontais de Curitiba, o texto do Decreto 982/2004 não só se sustenta ao interpretar a Lei Federal n 4.591/64 sobre incorporações imobiliárias como sendo uma lei de parcelamento do solo, como registra expressamente que não existe restrição na Lei Federal 6.766 para aprovação de condomínios horizontais, baseada em parecer jurídico. Assim como São Paulo, também considera condomínio como categoria de uso do solo.

Porto Alegre e Florianópolis, como na maioria das capitais estudadas, se valem da Lei Federal $n^{\circ} 4.591 / 64$ para viabilizar os condomínios horizontais fechados. No entanto, assim como Vitória/ES, Florianópolis procura mitigar o seu impacto ao limitar o número de unidades autônomas e exigir, além do percentual de áreas comunitárias internas ao empreendimento, a doação de área pública de lazer já implantada.

\section{Um cardápio de leis para a produção de lote urbanizado}

A construção do quadro sobre a as formas de produção de lotes previstas nas leis das capitais brasileira resultou em um verdadeiro cardápio legislativo: é totalmente possível o empreendedor escolher se produz a cidade fechada ou aberta. A legalidade existente em todas as capitais para a os empreendimentos horizontais fechados é um forte desestímulo para a expansão urbana na forma de "loteamentos abertos", em algumas leis até chamado de "loteamento padrão".

Não doação de áreas públicas, alta valorização do empreendimento, atendimento à demanda existente, marketing do oásis urbano e diferenciação do produto imobiliário são algumas razões para que o empreendedor e loteador optem para a produção do lote fechado. Outra razão da vantagem dos empreendimentos horizontais fechados 
é que a localização se torna uma condicionante relativa. Mesmo com uma vizinhança não convidativa, o enclave fortificado mitiga as deficiências de uma localização ao negar o entorno. Para o empreendedor, a expansão murada permite sobrevalorizar a terra em comparação com o loteamento tradicional.

Se a externalidades dos impactos dos condomínios horizontais é legalizada, não há demanda do setor imobiliário para se lotear via expansão urbana aberta.

Os resultados da pesquisa apontam que as leis de parcelamento do solo nas capitais brasileiras têm incitado a produção de tecidos desconexos com a cidade existente, carente de áreas públicas, em desacordo com a lei federal e em favor do mercado imobiliário.

Verificou-se que nas capitais brasileiras há uma regulação dúbia e contraditória: existem leis que regulam o parcelamento do solo, mas ao mesmo tempo os liberam via empreendimentos fechados. Adota-se a figura do loteamento nos moldes da L. F. 6.766/79, com destinação de áreas de lazer, áreas institucionais e sistema viário públicos, ao mesmo tempo em que é totalmente regulamentada a produção de lotes em condomínios fechados e suas variações, com requintes de aberrações urbanísticas.

O papel das leis das capitais sobre a produção de lotes tem sido regular para permitir a cidade fechada. As leis que restringem viram uma opção e a leis que flexibilizam a única escolha. Mesmo com tanta possibilidade de produzir lotes em empreendimentos fechados e não atender a lei federal de parcelamento do solo nas capitais brasileiras, caso a produção de condomínios horizontais e loteamentos fechados ainda esteja regular, a Lei 13.465/17 anistia e regulariza. Liberalmente, a legislação urbanística brasileira atual é voltada para produção da cidade fechada.

\section{Referências bibliográficas}

BRAGA, Roberto. Transferência de custos ambientais e urbanísticos na implantação de loteamentos fechados na cidade de Piracicaba-SP. Caderno de Geografia, v.23, n.39, 2013.

BRITO, Fausto e SOUZA, Joseane. Expansão Urbana nas grandes metrópoles: o significado das migrações intrametropolitanas e da mobilidade pendular na reprodução da pobreza. Revista São Paulo em Perpectiva, São Paulo, v. 19, n. 4, p. 48-63, 2005. ISSN 0102-8839 <http://dx.doi.org/10.1590/S0102-88392005000400003>.

BALTRUSIUS, Nelson e D'OTTAVIANO, Maria Camila L. (2009). Ricos e pobres, cada um em seu lugar: a desigualdade socioespacial na metrópole paulistana. Caderno CRH, Salvador, v.22, n.55, p.135-149. Jan/abr. <http://dx.doi.org/10.1590/S0103-49792009000100008>.

CALDEIRA, Teresa P. Enclaves Fortificados: a Nova Segregação Urbana. Estudos Cebrap, São Paulo, v. 47, p. 155-176, 1997.

Cidade de muros: crime, segregação e cidadania em São Paulo. São Paulo: Editora 34, 2003.

CORDEIRO, Gustavo Chaves. S. A natureza jurídica dos bens de uso comum nos condomínios fechados. In: FERNANDES, E; ALFONSIN, B. (org) A lei e a ilegalidade na produção do espaço urbano. Belo Horizonte: DelRey ; Lincoln Institut, 311-316, 2003.

GONÇALVES, Raquel .G.; MARRA, Natália. C. A privatização do planejamento urbano pelos condomínios horizontais: um desafio em expansão. In: Anais do Circuito de Debates Acadêmicos. IPEA. Brasília. 2012; 
IBGE, Síntese de Indicadores Sociais: Uma Análise das Condições de Vida da População Brasileira. 2013. <http://biblioteca.ibge.gov.br/visualizacao/livros/liv66777.pdf> Acesso em 06/06/2018.

LIMA, Daniela B. Do medo da violencia à condominiarização das cidades brasileiras: sobre as conequências socioespaciais da modificação da legislação federal de parcelamento do solo urbano. In: Anais do XIII ENANPUR - Encontro da Associação Nacional de Pós-Graduação e Pesquisa em Planejamento Urbano e Regional. Florianópolis,- Santa Catarina, Brasil, 2009.

MARINHO, Marla J; LEONELLI, Gisela C.V. A Expansão urbana privatizada: a lei e o mercado imobiliário no caso de Indaitatuba - SP. In: Anais do XVII ENANPUR, São Paulo. 2017.

LAGE, Selena Duarte Lage e. Loteamentos Fechados em Cidades Médias: reflexões a partir do estudo da implantação e impactos desses empreendimentos na cidade de Uberlândia, MG. Revista Brasileira de Assuntos Regionais e Urbanos.Goiânia, v.3, n.2, p.242-257, jul./dez, 2017.

LEONELLI, Gisela C. V. Loteamentos e condomínios: lei para que, lei para quem, mas qual lei? In: Anais do XV ENANPUR, Recife, 2013.

SILVA, M.F. P. S A expansão dos condomínios fechados no Brasil e no mundo: redimensionando o fenómeno. In: Anais do XIII ENANPUR - Encontro da Associação Nacional de Pós-Graduação e Pesquisa em Planejamento Urbano e Regional. Florianópolis, Santa Catarina, Brasi, 2009.

SPOSITO, Maria E. Reestruturação Urbana e Segregação Socioespacial no interior paulista. Revista Scripta Nova. Vol. XI, núm. 245 (11), 2017.

SPOSITO, Maria E.; GÓES, Eda. Espaços Fechados e Cidades. Editora Unesp. São Paulo, 2013.

SPOSITO, Maria Encarnação. Loteamentos fechados em cidades médias paulistas - Brasil. In: SPOSITO, Maria E.; SOBARZO, Oscar. Cidades médias: Produção do espaço urbano e regional. São Paulo: Expressão Popular, 2006, p.373-396.

PARQUOT, Terry (2009). Ghettos de Riches: tour du monde des enclaves résidentielles sécurisées. Paris, Ed. Perrin, 2009.

TURCZYN, Daniel T. Morfologia Urbana Contemporânea: contribuições para uma teoria das mutações urbanas. Tese de Doutoramento. Programa de Pós Graduação em Arquitetura, Tecnologia e Cidade. FEC UNICAMP, 2019.

\section{Referências legislativas}

BRASIL. 1964. Lei Federal n 4.591/1964. Dispõe sobre condomínio em edificações e incorporações imobiliárias. Senado Federal.

Lei $n^{\circ}$. 6.766, de 19 de Dezembro de 1979. Dispõe sobre o parcelamento do solo urbano e dá outras providências. Diário Oficial da União, Brasília, 1979.

CAMARA LEGISLATIVA DO DISTRITO FEDERAL. Lei n 4893, de 26/07/2012. Dispõe sobre loteamento fechado e dá outras providências.

. Lei Complementar n 854, de 15/10/2012. Atualiza a Lei Complementar $n^{\circ} 803$, de 25/04/2009, que aprova a Revisão do Plano Diretor de Ordenamento Territorial do Distrito Federal - PDOT e dá outras providências.

PREFEITURA MUNICIPAL DE ARACAJU. Lei Complementar n 42, de 04/10/2000. Institui o Plano Diretor de Desenvolvimento Urbano de Aracaju, cria o Sistema de Planejamento e Gestão Urbana e dá outras providências.

PREFEITURA MUNICIPAL DE BELÉM. Lei n 7399, de 11/01/1988. Dispõe sobre o parcelamento do solo do município de Belém.

Lei n 02/99 de 19/06/1999. Lei Complementar de Controle Urbanístico. Dispõe sobre o Parcelamento, Ocupação e Uso do Solo Urbano do Município de Belém e dá outras providências. 
PREFEITURA MUNICIPAL DE BELO HORIZONTE. Decreto n 16.208, de 20/01/2016. Regulamenta as Seções I, VI e VII do Capítulo III da Lei n 7.166, de 27 de agosto de 1996 e dá outras providências.

PREFEITURA MUNICIPAL DE BOA VISTA. Lei n 925, de 28/11/2006. Dispõe sobre parcelamento do solo urbano do município de Boa Vista e dá outras providências.

PREFEITURA MUNICIPAL DE CAMPO GRANDE. Lei complementar n74, de 06/11/2005. Dispõe sobre o Ordenamento do Uso e da Ocupação do solo do município de Campo Grande e dá outras providências.

PREFEITURA MUNICIPAL DE CUIABÁ. Lei Complementar n 56, de 09/11/1999. Dispõe sobre condomínios horizontais, também denominados conjuntos residenciais horizontais e dá outras providências.

. Lei Complementar n 389/11/2015. Disciplina o Uso e Ocupação do Solo no município de Cuiabá.

. Lei $n^{\circ} 6014$, de 14/12/2015. Altera a Lei n 1833, de 2206/1981, que dispõe sobre o parcelamento do solo rural para fins de formação de sítios de recreio.

PREFEITURA MUNICIPAL DE CURITIBA. Lei n²942, de 27/12/1966. Estabelece normas para aprovação de arruamentos, loteamentos e desmembramentos de terrenos no município de Curitiba e revoga a Lei $n^{\circ} 1650 / 58$.

Decreto Lei 982 de 26/10/2004. Dispõe sobre procedimentos para aprovação de Projetos de Construção sob a forma de condomínio residencial horizontal.

PREFEITURA MUNICIPAL DE FORTALEZA. Lei n 5122.A/1979 e Complementares.

Lei Complementar nº62, de 02/02/2009. Institui o Plano Diretor Participativo do Município de Fortaleza e dá outras providências.

PREFEITURA MUNICIPAL DE FLORIANÓPOLIS. Lei Complementar n 482, de 17/01/2014. Institui o Plano Diretor de Urbanismo do Município de Florinanópolis que dispões sobre a política de desenvolvimento urbano, o plano de uso e ocupação, os instrumentos urbanísticos e o sistema de gestão.

PREFEITURA MUNICIPAL DE GOIÂNIA. Lei n 7.042, de 27/12/1991. Dispõe sobre a aprovação e implantação, no município de Goiânia, de Planos Urbanísticos Integrados, define suas características, cria nova zona de uso e dá outras providências.

Lei $n^{\circ} 8760$, de 19/01/2009. Regulamenta o art 119, da Lei Complementar $n^{\circ} 171$, de 29/05/2007 e Lei Complementar nº 181 de 01/10/2008 que dispõe sobre conjuntos residenciais e dá outras providências.

PREFEITURA MUNICIPAL DE JOÃO PESSOA. Institui o Código de Urbanismo de João Pessoa.

Decreto N. ${ }^{\circ} 6.499$, de 20/03/2009. Consolida a Lei Complementar nº 054, de 23/12/2008 às disposições da Lei Complementar nº 03 de 30/12/1992.

PREFEITURA MUNICIPAL DE GOIÂNIA. Lei n 7.042, de 27/12/1991. Dispõe sobre a aprovação e implantação, no município de Goiânia, de Planos Urbanísticos Integrados, define suas características, cria nova zona de uso e dá outras providências.

Lei $n^{\circ} 8760$, de 19/01/2009. Regulamenta o art 119, da Lei Complementar no 171, de 29/05/2007 e Lei Complementar n 181 de 01/10/2008 que dispõe sobre conjuntos residenciais e dá outras providências.

PREFEITURA MUNICIPAL DE MACAPÁ. Lei Complementar n 30, de 21/06/2004. Dispõe sobre o parcelamento do solo urbano do município de Macapá e dá outras providências.

PREFEITURA MUNICIPAL DE MACEIÓ. Lei n 5.593 de 08/02/2007. Institui o Código de Urbanismo e Edificações do Município de Maceió, estabelece o zoneamento da cidade de acordo com os parâmetros de macrozoneamento do Plano Diretor e Desenvolvimento Urbano e dá outras providências. 
PREFEITURA MUNICIPAL DE MANAUS. Lei C. nº 003 de 16/01/2014. Dispõe sobre o Código de Obras e Edificações do Município de Manaus e dá outras providências.

Lei nº 004 de 16/01/2014. Dispõe sobre o Parcelamento do Solo Urbano do Município de Manaus e dá outras providências.

PREFEITURA MUNICIPAL DE NATAL. Lei Complementar n 082, de 21/06/2007. Dispõe sobre o Plano Diretor de Natal e dá outras providências.

PREFEITURA MUNICIPAL DE PALMAS. Lei Complementar n 37, de 05/05/2003. Altera dispositivos da Lei Complementar nº 58 de 16/09/2002.

Lei Complementar n 155, de 28/12/2007. Dispõe sobre a Política Urbana do Município de Palmas.

Lei Complementar $n^{\circ} 305$, de 02/10/2014. Altera a Lei $n^{\circ} 31$, de 07 de dezembro de 1989, que estabelece o Código Municipal de Obras

PREFEITURA MUNICIPAL DE PORTO VELHO. Lei Complementar nº 097, de 29/12/1999. Dispõe sobre o Parcelamento, uso e ocupação do solo do município de Porto Velho.

Lei n 1919, de 23/12/2010. “Dispõe sobre a permissão a titulo precário de uso das áreas públicas de lazer e das vias de circulação, para a constituição de loteamentos fechados no município de Porto Velho, e dá outras providências.

PREFEITURA MUNICIPAL DE RIO BRANCO. Lei n 1.611, de $27 / 10 / 2006$. "Aprova e Institui o novo Plano Diretor do Município de Rio Branco e dá outras providências".

. Lei n 1.993 de 19/07/2013. Dispõe sobre a implantação de loteamentos fechados e de condomínios horizontais de lotes em Rio Branco e dá outras providências.

PREFEITURA MUNICIPAL DO RIO DE JANEIRO. Lei Complementar n 111, de 1\%01/2011. Dispõe sobre a Política Urbana e Ambiental do Município, Institui o Plano Diretor de Desenvolvimento Sustentável do município do Rio de Janeiro e dá outras providências.

DECRETO no 322 de 03/03/1976. (Decreto Consolidado- Regulamento aprovado pelo Decreto $\left.n^{\circ} 25701 / 2005\right)$

PREFEITURA MUNICIPAL DE SALVADOR. Lei n 3200, de 21/06/1982. Dispõe sobre o parcelamento do solo urbano, cria incentivos para loteamentos populares e dá outras providências.

Lei $n^{\circ} 4607$ de 27/10/1992. Incentiva a oferta de lotes populares, dispõe sobre condomínios fechados e dá outras providências.

PREFEITURA MUNICIPAL DE SALVADOR. Lei n 8379, de 20/12/2012. Dispõe sobre a Lei de Ordenamento do Uso e Ocupação do Solo do município de Salvador e dá outras providências.

PREFEITURA MUNICIPAL DE SÃO LUÍS. Lei 3.253, 29/12/1992. Dispõe sobre o zoneamento, parcelamento, uso e ocupação do solo urbano e dá outras providências.

PREFEITURA DO MUNICÍPIO DE SÃO PAULO. Lei n 13.792 13/02/2004 .Dispõe sobre a criação de Condomínios Residenciais Fechados no Município de São Paulo, e da outras providencias.

Lei no 16.402 , de 22/03/2016. Disciplina o parcelamento, o uso e a ocupação do solo no Município de São Paulo, de acordo com a Lei n 16.050, de 31 de julho de 2014 - Plano Diretor Estratégico (PDE).

PREFEITURA MUNICIPAL DE PORTO ALEGRE. Lei Complementar $n^{\circ} 434$, de 1\%/12/1999. (Atualizada pela L.C. $n^{\circ}$ 667, de 03/01/2011). Dispõe sobre o desenvolvimento urbano no município de Porto Alegre, institui o Plano Diretor de Desenvolvimento Urbano Ambiental de Porto Alegre e dá outras providências.

PREFEITURA MUNICIPAL DE TERESINA. Lei Complementar n 3.561, de 20/10/2006. Dispõe sobre o parcelamento do solo urbano do Município de Teresina e dá outras providências. 